Journal of Fundamental and Applied Sciences

ISSN 1112-9867

Available online at

http://www.jfas.info

\title{
SQUARE WAVE VOLTAMMETRIC DETERMINATION OF LEAD IN COMMERCIAL KOHL USING A GLASSY CARBON ELECTRODE
}

\author{
M. A. Saha, M. Alia, A. Rebiai and T. Lanez* \\ VTRS Laboratory, University Centre of El-Oued, P.O. Box 789, 39000, El-Oued,
} Algeria

Received: 25 November 2011 / Accepted: 02 December 2011 / Published online: 31 December 2011

\begin{abstract}
A simple sensitive square wave voltammetric method for the determination of lead contamination of several kohl samples purchased from Algeria retail stores was developed using glassy carbon electrode. The peak current response of 5 standards aqueous solution of lead in $\mathrm{NaNO}_{3}$ as supporting electrolyte was observed showing a linear calibration curve in the concentration range of $4 \times 10^{-3}-2.5 \times 10^{-4} \mathrm{~mol} / \mathrm{l}$ of lead. Over this concentration range, the equation obtained from the linear calibration graph for lead is $Y=0.00068+0.0093 x$ with a correlation coefficient of $r^{2}=0.987$. Following this step, the potential of an aqueous solution of $12 \mathrm{kohl}$ samples containing $2 \mathrm{M}$ nitric acid solution as supporting electrolyte is then swept in the same range of potential (-400 to $-700 \mathrm{mV}$ ). The amount of lead is then deduced using the linear calibration graph for lead. The results showed up to $52.14 \%$ of lead present in kohl, this concentration was over the safe limits of lead set by the world health organization standards. However; only five commercial samples of kohl tested contained less than $0.001 \%$ lead. Complete recovery of lead from the kohl was obtained by simple nitric acid digestion.
\end{abstract}

Key words: Square wave voltammetry, kohl, lead, surma.

\section{INTRODUCTION}

Kohl is traditional cosmetic eyeliner used in the Middle East, North Africa and Asia. This powdery substance, generally dark in color, is also named Surma, Kajal in some countries such as India, Pakistan and Iran [1].

Author Correspondence, e-mail: lanezt@gmail.com

ICID: 1020752 
Kohl is also associated with spiritual beliefs and medical (protection against eye infections)[2]. The "sauna", the religious behavioral guidelines of the Islamic belief identifies kohl as a free lead substance, mainly composed of antimony. However, analysis performed on kohl used today has shown low concentration of antimony, less than $0.1 \%$ while the main composition of kohl is lead [3-4]. Because antimony is a substance more scarce and expensive, it was gradually replaced through time by lead.

However contamination of kohl by lead may may be a pervasive source of lead poisoning, which usually occurs from repeated exposure to small amounts of lead.

Lead is a toxic metal that can be harmful to a human health. Once absorbed by the body, lead can damage the brain, nervous system, reproductive system, kidneys and other parts of the body [5]. The high toxicity of lead is du to its stability and accumulation in human body.

Recent reports showed that lead poisoning in childhood can cause a lifetime negative effect on intelligence and learning abilities, the effects of which persist long after the initial exposure to lead[6]. Kohl contaminated with lead could be the cause of countless unexplained third-world infant deaths, and a significant contributory factor to early mortality?

Several methods have been reported for the analysis of lead, such as atomic absorption spectrometry [7,8], atomic emission spectrometry [9] high performance liquid chromatography [10], inductively coupled plasma-mass spectrometry [11] and neutron activation analysis [12]. However, these techniques have some disadvantages such as complicated operation, high cost of maintenance expensive apparatus and requiring well-controlled experimental conditions. However, the electrochemical methods for the determination of lead are of the most favorable methods because of their low cost and easy operation [13]. The aim of this study is to investigate the possibility of using square wave voltammetry techniques for quantifying lead in commercial kohl.

\section{SQUARE WAVE VOLTAMMETRY TECHNIQUES}

The square wave voltammetric waveform arises from the superimposition of two waveforms, an incremental staircase potential of amplitude $\Delta E$, which has a square wave amplitude waveform superimposed on it of magnitude E[14,15]. The current is sampled at the lower potential of the magnitude and then at the higher potential, and the 
difference between these two currents is the peak current which is proportional to the chemical species concentration over a given concentration range, and is given by:

$$
d i_{p}=\frac{2 r i^{2} F^{2} r D C E}{R T}
$$

where $r$ is the electrode radius, D the diffusion coefficient of the electroactive species in solution, $\mathrm{C}$ its concentration, $E$ step potential, $\mathrm{F}$ is the Faraday constant, $\mathrm{R}$ is the gas constant, and $\mathrm{T}$ is the temperature.

\section{MATERIAL AND METHODS}

\subsection{Chemicals}

All reagents were of analytical grade.

Lead biacetate (99.5\%), sodium nitrate (99\%), nitric acid (99\%), acetic acid (99\%), were all purchased from biochem chemopharma Co.

\subsection{Kohl simples}

Samples of kohl were purchased from Algeria retail stores, most of these samples originated from Pakistan, India, and Saudi Arabia.

\subsection{Instrumentation and software}

Square wave voltammetry measurements were performed using PGZ301 potentiostat (radiometer analytical SAS) and a voltammetric cell with a volumetric capacity of 50 $\mathrm{mL}$ containing a glassy carbon electrode (GCE) working electrode (radiometer analytical SAS), a Pt wire counter electrode, and an $\mathrm{Hg} / \mathrm{Hg}_{2} \mathrm{Cl}_{2}$ reference electrode (3.0 $\mathrm{M} \mathrm{KCl}$ ). Solutions were deoxygenated with high purity nitrogen for 3 min prior to each experiment. Data acquisitions were accomplished with a Pentium IV (CPU 3.0 GHz and RAM $1 \mathrm{~Gb}$ ) microcomputer using VoltaMaster software version 7.08 (radiometer analytical SAS). Graphs plot and calculus were carried out using OriginLab software version 2.0 (Integral Software, France). 


\subsection{Preparation of standard solution of lead (II)}

The stock solutions of lead (II) were prepared by dissolving $1.3 \mathrm{~g}$ of lead diacetate in $1 \mathrm{~L}$ aqueous solution of sodium nitrate $(0.1 \mathrm{~mol} / \mathrm{L})$ to give $4.10^{-3} \mathrm{~mol} / \mathrm{L}$ lead (II) standard solution.

\subsection{Digestion of kohl samples}

A sample of kohl $(100 \mathrm{mg})$ was dissolved in $50 \mathrm{~mL}$ aqueous nitric acid solution $(2 \mathrm{M})$ and the resulting suspension was stirred for $2 \mathrm{~h}$ at room temperature. It was then filtered, the filtrate was transferred to the voltammetric cell and the electrochemical measurements were carried out.

\section{RESULTS AND DISCUSSION}

\subsection{Square wave voltammetry measurements}

Square wave voltammetric measurements were run from -400 to $-700 \mathrm{mV}$ using an electrochemical cell with a volumetric capacity of $50 \mathrm{~mL}$ containing a glassy carbon electrode working electrode (radiometer analytical SAS), a Pt wire counter electrode, and an $\mathrm{Hg} / \mathrm{Hg}_{2} \mathrm{Cl}_{2}$ reference electrode (saturated with $\mathrm{KCl}$ ). The parameters for square wave voltammetric measurements were: the potential step was $15 \mathrm{mV}$, the square wave amplitude was $50 \mathrm{mV}$, and the scan rate was $3 \mathrm{mV} / \mathrm{s}$. All measurements were carried out at room temperature $\left(26 \pm 2{ }^{\circ} \mathrm{C}\right)$.

The recorded voltammograms of lead solutions in the range of concentrations $4,2,1$, 0.5, $0.25 \mathrm{mmol} / \mathrm{L}$ are represented in (Fig.1). 


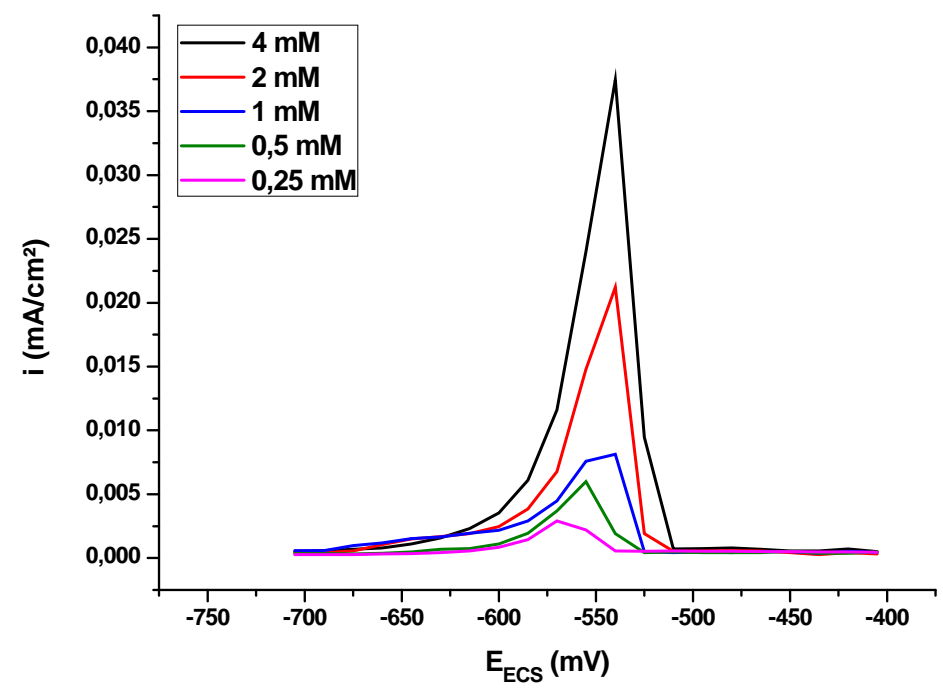

Fig.1. Square wave voltammograms referring to different $\mathrm{Pb}(\mathrm{II})$ concentrations in aqueous $\mathrm{NaNO}_{3}(0.01 \mathrm{M})$ at a glassy carbon electrode, with step potential of $50 \mathrm{mV}$, square wave amplitude of $15 \mathrm{mV}$ and scan rate of $3 \mathrm{mV} / \mathrm{s}$.

The calibration graph is obtained by plotting the peak current of the anodic curve of the voltammogram of each sample of the standard versus its concentration. Lead diacetate was used as a standard in the calculation of the concentration of studied kohl samples because its anodic peak current displays excellent linearity toward lead concentrations. As it can be seen from figure (1) there is an increase in oxidation peaks current with the increase in lead concentrations which leads to a linear relation between these two parameters.

The oxidation peaks current are summarized in (Table 1).

Table 1. Peaks current obtained from SW voltammogrames of lead

\begin{tabular}{|c|c|}
\hline $\mathrm{C}(\mathrm{mmol} / \mathrm{L}$ & $d \dot{i}_{p}\left(\mathrm{~mA} . \mathrm{cm}^{-2}\right)$ \\
\hline 4 & 0,03746 \\
\hline 2 & 0,02122 \\
\hline 1 & 0,00813 \\
\hline 0.5 & 0,006 \\
\hline 0.25 & 0,00292 \\
\hline
\end{tabular}


The equation obtained from the linear calibration graph in the studied concentration range for lead (II) in aqueous $\mathrm{NaNO}_{3}$ is $Y=0.00068+0.0093 x$ (where $y$ represents the value of oxidation current and $x$, the value of lead (II) concentrations, expressed as $\mathrm{mmol} / \mathrm{L}$ ) with a correlation coefficient of $\mathrm{R}^{2}=0.987$. Results obtained are shown in (Fig.2).

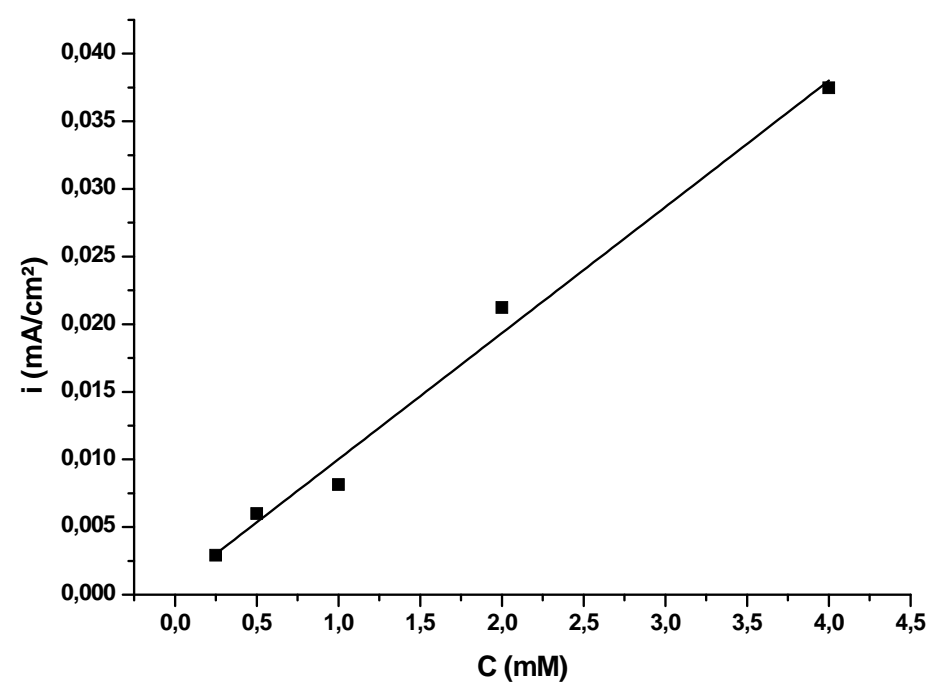

Fig.2. Calibration curve obtained from $\mathrm{SW}$ voltammograms for different $\mathrm{Pb}(\mathrm{II})$ concentrations at $3 \mathrm{mV} / \mathrm{s}$ in aqueous $\mathrm{NaNO}_{3}(0.01 \mathrm{M})$.

\subsection{Square wave Voltammetric lead determination}

$50 \mathrm{~mL}$ of the digested kohl solution was introduced into the electrochemical cell and the oxidation peak current of the voltammogram was recorded. The above procedure was repeated for all samples. The concentration of lead in kohl samples was obtained using the density of the oxidation peak current of the corresponding voltammogram. (Fig.3) shows different voltammogrames of the twelve studied kohl samples. 


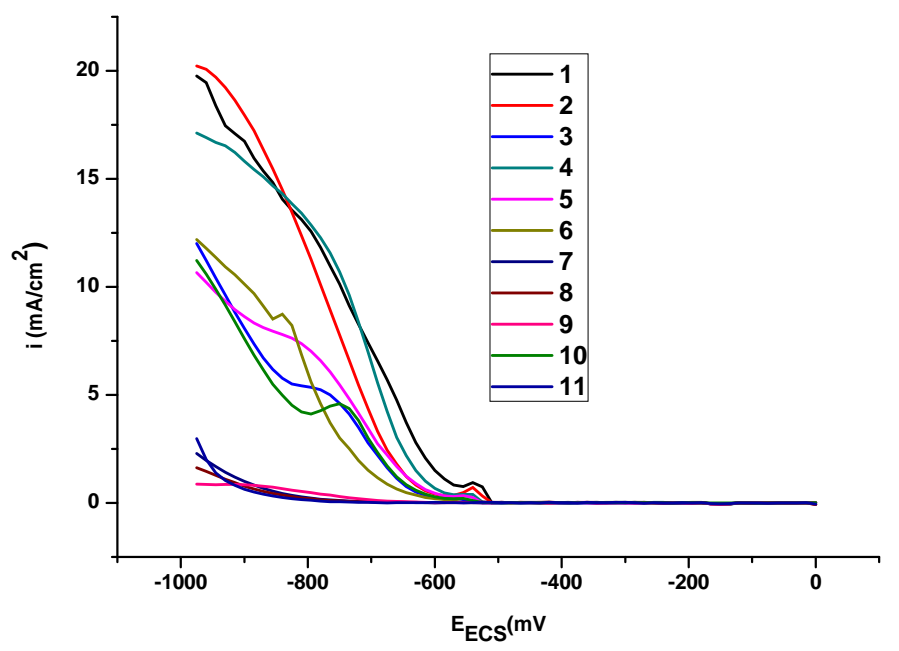

Fig.3. Square wave voltammograms referring to different kohl concentrations in aqueous $\mathrm{HNO}_{3}(2 \mathrm{M})$ at a glassy carbon electrode, with step potential of $50 \mathrm{mV}$, square wave amplitude of $15 \mathrm{mV}$ and scan rate of $3 \mathrm{mV} / \mathrm{s}$.

In order to get a better reading of peak current density, the voltammograms are retraced in the range of potential: -480 to $-585 \mathrm{mV}$ as shown on (Fig.4). The potential shift is probably du to the increase of the resistance solution.

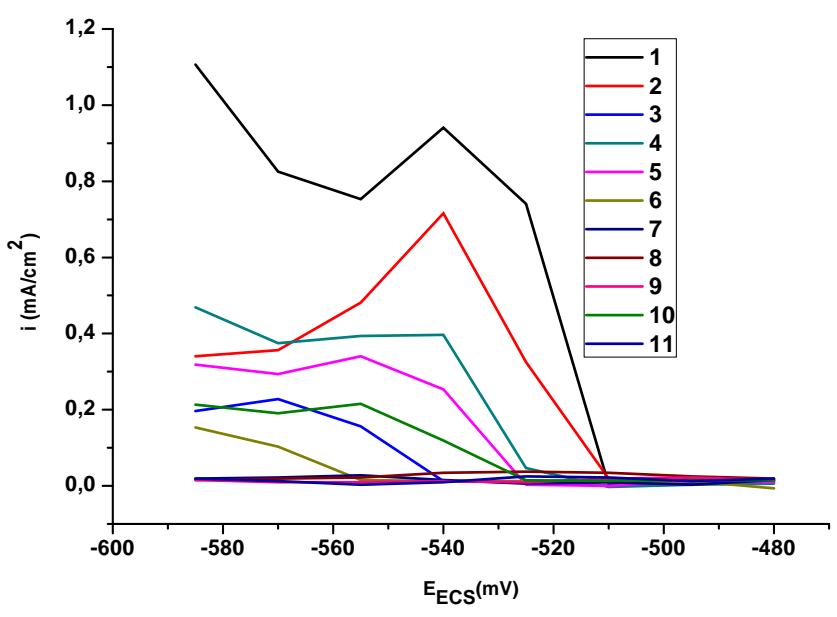

Fig.4.Square wave voltammograms referring to different kohl samples retraced in the range of potential: -480 to $-585 \mathrm{mV}$

Table 2 shows kohl samples, their origin and level of contamination of lead, all samples were tested in replicates. 
Table 2. Lead content of kohl samples

\begin{tabular}{|c|c|c|c|c|}
\hline Sample & Origin & $d i_{p}\left(\mathrm{~mA} / \mathrm{cm}^{2}\right)$ & Lead $\%$ & Lead $\%[16]$ \\
\hline 1 & Unknown & 0.0228 & 24,56 & 34,09 \\
\hline 2 & Saudi Arabia & 0.0397 & 43,33 & 36,13 \\
\hline 3 & Unknown & 0.0341 & 37,11 & 31,80 \\
\hline 4 & Unknown & 0.0153 & 16,23 & 0,60 \\
\hline 5 & Unknown & $*$ & $<0,0001$ & $<0.01$ \\
\hline 6 & India & $*$ & $<0,0001$ & $<0.01$ \\
\hline 7 & Unknown & $*$ & $<0,0001$ & $<0.01$ \\
\hline 8 & Pakistan & 0.0455 & 49,21 & 32,21 \\
\hline 9 & Saudi Arabia & $*$ & $<0,0001$ & $<0.01$ \\
\hline 10 & Unknown & 0.094 & 52,14 & 31,67 \\
\hline 11 & Saudi Arabia & 0.07156 & 39,37 & 35,82 \\
\hline 12 & Saudi Arabia & $*$ & $<0,0001$ & $<0.01$ \\
\hline
\end{tabular}

*Value below the detection limit.

\section{CONCLUSION}

Square wave voltammetric measurements described in this work was successfully applied for the determination of lead contamination of kohl using a glassy carbon electrode. Among the 12 samples of kohl analyzed in this work, seven was found to contain high detectable amounts of lead when digested with $\mathrm{HNO}_{3}$. The highest concentration of lead in studied samples was found to be $52.14 \%$; this level is considered to be over the safe limits according to the world health organization standards. The other five samples were found to be below the detection limit of lead by square wave voltammetry which is less than $0.001 \%$.

\section{REFERENCES}

[1] Food and Drugs Administration (FDA), 2003. Kohl, Kajal, al Kahl, or Surma : By any name, a source of Lead poisoning. Tiré de FDA www.cfsan.fda.gov/ dms/coskohl.html.

[2] Parry C., Eaton J. Khôl: A lead hazardous makeup from the Third World to the first World, Environmental Health Perspectives. 1991, 94, 121-3.

[3] Topham J. Traditional Crafs of Saudi Arabia, Stacey International, London. 1981.

[4] Ross H. The Art of Arabian Costume, Stacey International, London. 1981. 
[5] Agusa T., Kunito T., Ramu K., Chamnan C., Trang P. T. K., Minh T. B., Subramanian A., Iwata H., Viet P.H., Tana T.S. and Tanabe S. Lead contamination and its human health effects in India, Vietnam and Cambodia, Biomed Res. Traces Elements. 2006, 17, 413-416.

[6] Needleman H., Schell A., Bellinger B., Leviton A., Allred E. The long term effects of exposure to low doses of lead in childhood, N. Engl. J. Med. 1990, 332(2), 83-88.

[7] Zacharia A., Gucer S., Izgi B., Chebotarev A., Karaaslanm H. Talanta. 2007, 72, 825 .

[8] Mhaske H. P., Vaidya V. V., Shailajan S., Singh G., Dalvi K. M. Determination of some heavy metals from medicinal plants, Pueraria tuberose, by atomic adsorption spectrometry technique, Nat. Environ. Poll. Technol. 2006, 5, 389-391.

[9] Zhou Y. J., Wang G., Zhou J., Tao G. Determination of trace amounts of lead, arsenic, nickel and cobalt in high-purity iron oxide pigment by inductively coupled plasma atomic emission spectrometry after iron matrix removal with extractantcontained resin, Anal. Chim. Acta. 2007, 584, 204-209.

[10] Hu Q., Yang G., Li H., Tai X., Yin J. Study on Determination of Seven Transition Metal Ions in Water and Food by Microcolumn High-Performance Liquid Chromatography, J. Bull. Korean Chem. Soc. 2004, 25(5), 694-698.

[11] Dias L., Pierre F., Maia T. D. S., Mesquita da Silva S. M., Frescura M. A., Welz V. L., Curtius B. J. Spectrochim. Acta Part B. 2003, 57.

[12] Ayenimo J. G., Yusuf A. M., Adekunle A. S., Makinde O. W. Heavy Metal Exposure from Personal Care Products, Bull Environ Contam Toxicol. 2010, 84, 8-14.

[13] Niazi A., Sharifi S., Amjadi E. Least-squares support vector machines for simultaneous voltammetric determination of lead and tin: A comparison between LSSVM and PLS in voltammetric data, J. Electroanal Chem. 2008, 623, 86-92.

[14] Osteryoung J., O’Dea J. J., Bard A. J.1986, Electroanal Chem. Vol 14, M. Dekker, Ney York, 209p.

[15] Osteryoung J., in M. I. Montenegro et al. 1991, Microelectrodes, Theory and Applications, Kluwer, Dordrecht, 139.

[16] Lanez T., Rebiai A., Saha M. A. and Alia M.; International Journal of Toxicology and Applied Pharmacology. 2011, 2(1), 21-24. 
How to cite this article

Saha M A, Alia M, Rebiai A and Lanez T. Square wave voltammetric determination of lead in commercial kohl using a glassy carbon electrode. J Fundam Appl Sci. 2011, $3(2), 155-164$. 